Fixed Point Theory, 22(2021), No. 1, 279-298

DOI: $10.24193 /$ fpt-ro.2021.1.20

http://www.math.ubbcluj.ro/ nodeacj/sfptcj.html

\title{
BOUNDARY VALUE PROBLEMS FOR FRACTIONAL-ORDER DIFFERENTIAL INCLUSIONS IN BANACH SPACES WITH NONDENSELY DEFINED OPERATORS
}

\author{
VALERI OBUKHOVSKII*, PIETRO ZECCA** AND MARIA AFANASOVA*** \\ *Faculty of Physics and Mathematics, Voronezh State Pedagogical University, \\ 394043 Voronezh, Russia \\ E-mail: valerio-ob2000@mail.ru \\ (Corresponding author) \\ ${ }^{* *}$ Università degli Studi di Firenze, Via Santa Marta 3, 50139 Firenze, Italy \\ E-mail:zecca@unifi.it \\ *** Faculty of Physics and Mathematics, \\ Voronezh State Pedagogical University, 394043 Voronezh, Russia \\ E-mail: marya.afanasowa@yandex.ru
}

\begin{abstract}
We consider a nonlocal boundary value problem for a semilinear differential inclusion of a fractional order in a Banach space assuming that its linear part is a non-densely defined HilleYosida operator. We apply the theory of integrated semigroups, fractional calculus and the fixed point theory of condensing multivalued maps to obtain a general existence principle. An example of a concrete realization of this result is also given. Some important particular cases including a nonlocal Cauchy problem, periodic and anti-periodic boundary value problems are presented.

Key Words and Phrases: Fractional differential inclusion, boundary value problem, nonlocal Cauchy problem, periodic problem, Hille-Yosida operator, integrated semigroup, measure of noncompactness, fixed point, topological degree, multivalued map, condensing map.

2020 Mathematics Subject Classification: 34B10, 34A08, 34A60, 34C25, 34G25, 47D62, 47H04, 47H08, 47H10, 47H11.
\end{abstract}

Acknowledgements. V. Obukhovskii and M. Afanasova are supported by the Ministry of Education and Science of the Russian Federation in the frameworks of the project part of the state work quota (Project No 1.3464.2017/4.6) and V. Obukhovskii also by the RFBR grant 17-51-52022. P. Zecca is partially supported by the Università di Firenze grant and by G.N.A.M.P.A. of I.N.d.A.M.

\section{REFERENCES}

[1] M. Adimy, H. Bouzahir, K. Ezzinbi, Existence for a class of partial functional differential equations with infinite delay, Nonlinear Anal. - TMA, 46(2001), no. 1, 91-112.

[2] R.P. Agarwal, D. Baleanu, J.J. Nieto, D.F.M. Torres, Y. Zhou, A survey on fuzzy fractional differential and optimal control nonlocal evolution equations, J. Comput. Appl. Math., 339(2018), 3-29. 
[3] B. Ahmad, J.J. Nieto, A. Alsaedi, M.H. Aqlan, A coupled system of Caputo-type sequential fractional differential equations with coupled (periodic/anti-periodic type) boundary conditions, Mediterr. J. Math., 14(2017), art. 227, 15 pp.

[4] C.T. Anh, T.D. Ke, On nonlocal problems for retarded fractional differential equations in Banach spaces, Fixed Point Theory, 15(2014), no. 2, 373-392.

[5] W. Arendt, Resolvent positive operators, Proc. London Math. Soc., 54(3)(1987), no. 2, 321-349.

[6] W. Arendt, Vector-valued Laplace transforms and Cauchy problems, Israel J. Math., 59(1987), no. $3,327-352$.

[7] W. Arendt, C.J.K. Batty, M. Hieber, F. Neubrander, Vector-valued Laplace Transforms and Cauchy Problems, Monographs in Mathematics, 96. Birkhauser Verlag, Basel, 2001.

[8] A.V. Arutyunov, V. Obukhovskii, Convex and Set-Valued Analysis. Selected Topics, De Gruyter Graduate, De Gruyter, Berlin, 2017.

[9] I. Benedetti, V. Obukhovskii, V. Taddei, On noncompact fractional order differential inclusions with generalized boundary condition and impulses in a Banach space, J. Funct. Spaces, 2015, art. ID 651359, 10 pp.

[10] Yu.G. Borisovich, B.D. Gelman, A.D. Myshkis, V.V. Obukhovskii, Topological methods in the theory of fixed points of multivalued mappings, (Russian), Uspekhi Mat. Nauk, 35(1980), no. 1, 59-126; English translation: Russian Math. Surveys, 35(1980), no.1, 65-143.

[11] G. Da Prato, E. Sinestrari, it Differential operators with nondense domain, Ann. Scuola Norm. Sup. Pisa Cl. Sci., 14(4)(1988), no. 2, 285-344.

[12] Z. Ding, A.G. Kartsatos, Nonresonance problems for differential inclusions in separable Banach spaces, Proc. Amer. Math. Soc., 124(1996), no. 8, 2357-2365.

[13] L. Górniewicz, Topological Fixed Point Theory of Multivalued Mappings, Second ed., Topological Fixed Point Theory and Its Applications, vol. 4. Springer, Dordrecht, 2006.

[14] D.H. Hyman, On decreasing sequences of compact absolute retracts, Fund Math., 64(1969), 91-97.

[15] M. Kamenskii, V. Obukhovskii, P. Zecca, Condensing Multivalued Maps and Semilinear Differential Inclusions in Banach Spaces, De Gruyter Series in Nonlinear Analysis and Applications, 7. Walter de Gruyter, Berlin - New York, 2001.

[16] T.D. Ke, V. Obukhovskii, N.-C. Wong, J.-C. Yao, On a class of fractional order differential inclusions with infinite delays, Appl. Anal., 92(2013), no. 1, 115-137.

[17] H. Kellerman, M. Hieber, Integrated semigroups, J. Funct. Anal., 84(1989), no.1, 160-180.

[18] A.A. Kilbas, H.M. Srivastava, J.J. Trujillo, Theory and Applications of Fractional Differential Equations, North-Holland Mathematics Studies, vol. 204, Elsevier Science B.V., 2006.

[19] D. Kravvaritis, N.S. Papageorgiou, A boundary value problem for a class of evolution inclusions, Comment. Math. Univ. St. Paul., 40(1991), no. 1, 29-37.

[20] G. Marino, Nonlinear boundary value problems for multivalued differential equations in Banach spaces, Nonlinear Anal., 14(1990), no. 7, 545-558.

[21] I.V. Mel'nikova, A.I. Filinkov, Integrated semigroups and C-semigroups. Well-posedness and regularization of operator-differential problems, (Russian), Uspekhi Mat. Nauk 49(1994), no. 6, 111-150; English translation in Russian Math. Surveys, 49(1994), no. 6, 115-155.

[22] F. Neubrander, Integrated semigroups and their applications to the abstract Cauchy problem, Pacific J. Math., 135(1988), 111-155.

[23] V.V. Obukhovskii, Semilinear functional-differential inclusions in a Banach space and controlled parabolic systems, Soviet J. Automat. Inform. Sci., 24(1991), no. 3, 71-79.

[24] V. Obukhovskii, B. Gel'man, Multivalued Maps and Differential Inclusions. Elements of Theory and Applications, World Scientific Publishing Co., Hackensack, NJ, 2020.

[25] V. Obukhovskii, P. Zecca, On boundary value problems for degenerate differential inclusions in Banach spaces, Abstr. Appl. Anal., 2003, no. 13, 769-784.

[26] V. Obukhovskii, P. Zecca, On semilinear differential inclusions in Banach spaces with nondensely defined operators, J. Fixed Point Theory Appl., 9 (2011), no. 1, 85-100.

[27] N.S. Papageorgiou, Boundary value problems for evolution inclusions, Comment. Math. Univ. Carolin., 29(1988), no. 2, 355-363. 
[28] N.S. Papageorgiou, Boundary value problems and periodic solutions for semilinear evolution inclusions, Comment. Math. Univ. Carolin., 35(1994), no. 2, 325-336.

[29] I. Podlubny, Fractional Differential Equations, Academic Press, San Diego, 1999.

[30] H.R. Thieme, Integrated semigroups and integrated solutions to abstract Cauchy problems, J. Math. Anal. Appl., 152, no.2, 416-447.

[31] P. Zecca, P.L. Zezza, Nonlinear boundary value problems in Banach space for multivalued differential equations on noncompact intervals, Nonlinear Anal., 3(1979), no. 3, 347-352.

[32] Z. Zhang, B. Liu, Existence results on nondensely defined fractional evolution differential inclusions, J. Appl. Math., 2012, art. ID 316850, 19 pp.

[33] Y. Zhou, Fractional Evolution Equations and Inclusions: Analysis and Control, Elsevier Academic Press, London, 2016.

Received: December 19, 2018; Accepted: February 26, 2019. 
